\title{
Advantages of the Green Solid State FSW over the Conventional GMAW Process
}

\author{
Hasan I. Dawood, ${ }^{1,2}$ Kahtan S. Mohammed, ${ }^{1}$ and Mumtaz Y. Rajab ${ }^{3}$ \\ ${ }^{1}$ School of Materials Engineering, Universiti Malaysia Perlis, Taman Muhibah-Jejawi, 02600 Arau, Perlis, Malaysia \\ ${ }^{2}$ Chemical Engineering Department, AL-Qadisiyah University, Iraq \\ ${ }^{3}$ Mechanical Engineering Department, AL-Qadisiyah University, Iraq \\ Correspondence should be addressed to Hasan I. Dawood; hassanissa1972@gmail.com
}

Received 10 January 2014; Revised 15 March 2014; Accepted 17 March 2014; Published 28 May 2014

Academic Editor: Achilles Vairis

Copyright (C) 2014 Hasan I. Dawood et al. This is an open access article distributed under the Creative Commons Attribution License, which permits unrestricted use, distribution, and reproduction in any medium, provided the original work is properly cited.

\begin{abstract}
The present work is an experimental comparison between the friction stir welding (FSW) and the conventional gas metal arc welding (GMAW) in joining of $\mathrm{Al}$ alloys. Two sets of $3 \mathrm{~mm}$ thick aluminum strip pairs were friction stir welded in a regular butting joint configuration. Two rotational speeds of $1750 \mathrm{rpm}$ and $2720 \mathrm{rpm}$ were utilized to perform the FSW process. The axial force and the transverse speed were kept constant at $6.5 \mathrm{KN}$ and $45 \mathrm{~mm} / \mathrm{min}$, respectively. Cylindrical tool shoulder and pin geometry were selected. Strip pairs of other similar sets were butt jointed using the conventional GMAW. The welding quality, power input, and macrostructure and microstructure of the butted joints were examined. The types of the fumes and the amount of the released gases were measured and compared. The results showed that the solid state FSW is green, environment-friendly, and of superior welding properties compared to the conventional GMAW.
\end{abstract}

\section{Introduction}

FSW is a solid state welding process which can afford a high quality of welds even for materials that are unmanageable with conventional welding such as aluminum. It is a clean, environment-friendly, and nonharmful process as it is accompanied by neither an arc formation and radiation nor toxic gas emission. It has low heat input and almost no welds finishing costs $[1,2]$. FSW gives several advantages over other welding techniques for joining various alloys, especially light alloys [3]. Owing to certain properties such as light weight, high strength to weight ratio, and good corrosion resistance, aluminum alloys are used in wide applications, including aerospace, automobile industries, shipbuilding, and train and tram wagons. They are also used in offshore structures and bridge construction. So far FSW has been widely applied to welding of low melting alloys which are difficult to be joined by any other conventional fusion welding such as AlLi 2195 alloy [4]. The process and terminology of FSW are schematically represented in Figure 1.

During FSW, heat input for welding is provisioned by the rubbing action of the tool shoulder with the top surface of the welded piece and by the plastic dissipation of the mechanical energy generated by the tool pin [5]. However, Roy et al. [6] and Hirata et al. [7] reported that the heat flow from the pin is relatively small compared to flow from the shoulder and thus it can be ignored. The heat input creates a softened plasticized metal around the tool and facilitates its transverse movement along the joint line. The plasticized metal is mixed, sheared, and extruded around the rotating tool pin in the vertical direction under the applied axial force. Eventually, the plasticized metal is forged by the contact of the tool shoulder and the pin resulting in a solid phase bond between the two pieces. During the welding process, advancing side is the side which the velocity vector of rotational speed is in the same direction with the welding speed and the other side which represent the retreating side. The FSW process leads to the appearance of thermomechanically affected zone (TMAZ), a heat affected zone (HAZ), and a nugget zone (NZ) which is of a vase-like shape in the central part of the TMAZ. The main FSW parameters that determine the quality of the welded joint are the tool plunge force, the tool rotation speed, and the travel or traverse speed [8]. 


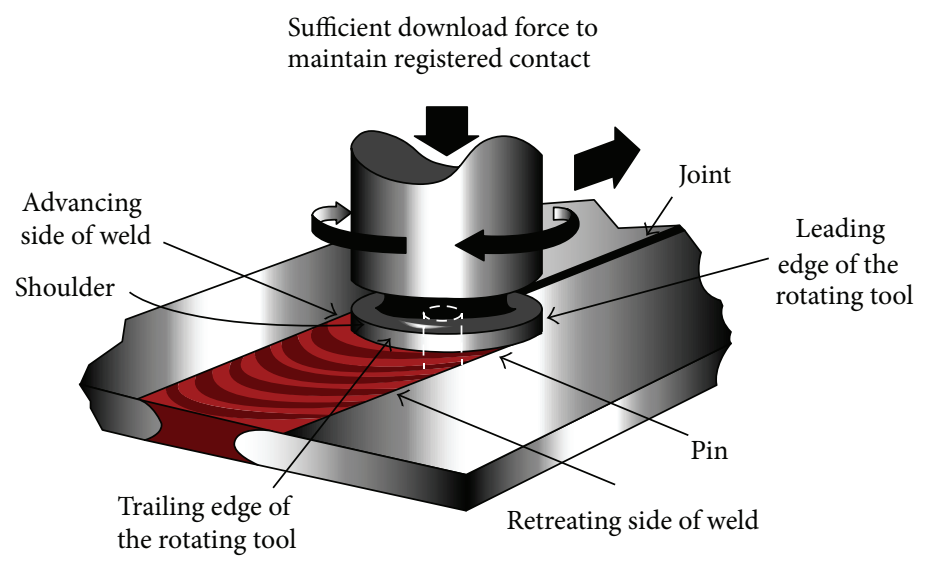

FIGURE 1: The schematic representation of FSW process.

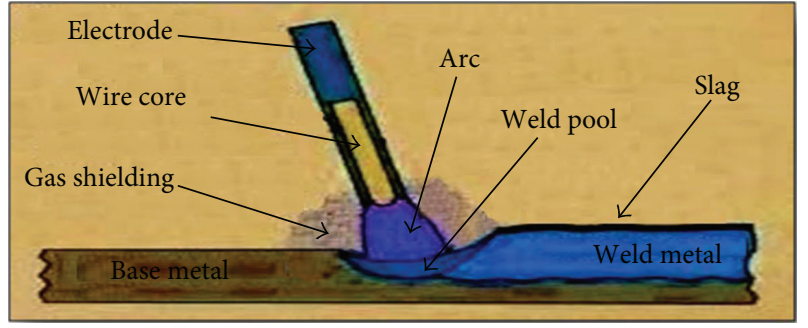

FIGURE 2: The schematic diagram of the welding process by GMAW.

GMAW is a conventional arc welding process [9]. Schematic representation of this process is shown in Figure 2 [9]. Throughout welding, heat input is an important characteristic; it influences the cooling rate and consequently the mechanical properties and the metallurgical structure of both the WZ and the HAZ [10]. GMAW welding process is performed at temperatures above the melting temperature of the workpiece. The higher temperature process needs higher power and can induce lots of defects in the welded piece such as distortion, cracking, and higher residual stresses which result in inferior mechanical properties [8].

In this study, two sets of $3 \mathrm{~mm}$ thick aluminum strip pairs were friction stir welded together at rotational speeds of $1750 \mathrm{rpm}$ and $2720 \mathrm{rpm}$. Welding process for another similar set of pairs was repeated using the conventional GMAW. Several papers are found comparing FSW with different conventional fusion arc welding processes; few of them are on welding of $\mathrm{Al}$ alloy $[1,11,12]$. The aim of this paper is to study the influence of FSW and GMAW on microstructure evolution and the quality of the $\mathrm{Al}-\mathrm{Al}$ weld joints and to assess their impact on the environment.

\section{Materials and Experimental Procedures}

$3 \mathrm{~mm}$ thick $1030 \mathrm{Al}$ strips with a nominal chemical composition of $0.114 \% \mathrm{Si}, 0.405 \% \mathrm{Fe}, 0.084 \% \mathrm{Cu}, 0.011 \% \mathrm{Mn}, 0.032 \%$ $\mathrm{Mg}, 0.017 \% \mathrm{Ti}$ and $\mathrm{Al}$ balance were used in this investigation. The FSW and the GMAW joints were of butt type. They were performed on a milling machine. Prior to welding, the metal

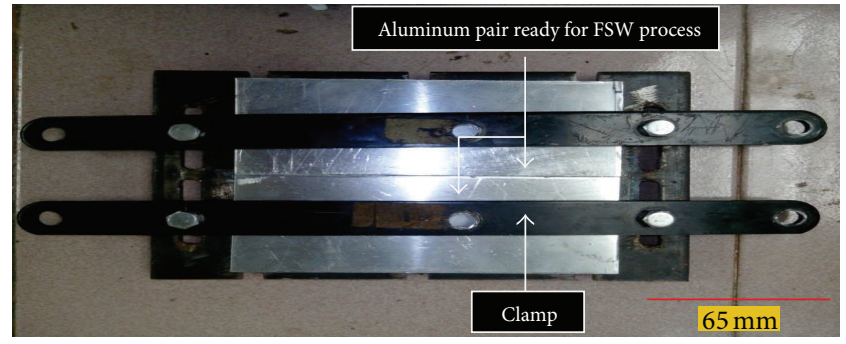

FIGURE 3: Photograph of the clamped Al strips.

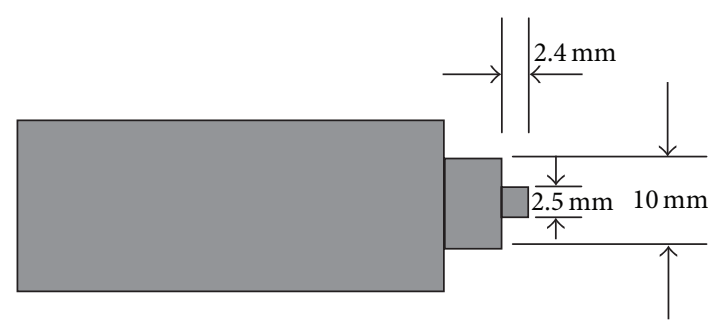

FIGURE 4: The tool shoulder and pin configuration diagram [8].

pairs were cleaned using acetone to remove any grease and stains that may affect the quality of welding. The metal pair was fixed by clamps to prevent any movement during the welding process as shown in Figure 3.

The horizontalness of the clamped pair on the milling machine was assured by horizontal level indicator for all Al-Al weld joints. Figure 4 shows that the utilized tool dimensions (shoulder and pin) were made of medium carbon steel $(0.424 \%$ C, $0.727 \% \mathrm{Mn}, 0.013 \% \mathrm{P}$, and $0.17 \% \mathrm{Si}$, and $\mathrm{Fe}$ balance). The tool was heat-treated and quenched to RC 56 . The vertical milling machine used in this work was about 3 horsepower (2237 watts).

In GMAW, the type of the welding current was a DC electropositive current and the shielding gas used was pure argon. The diameter of the aluminum filler wire was $1.0 \mathrm{~mm}$. It had chemical composition of Mn (0.05-0.20\%), Si (0.25\%), $\mathrm{Fe}(0.40 \%)$, and $\mathrm{Cr}(05-0.20 \%)$ and $\mathrm{Al}$ balance with the code 
reference of ER5356. The heat input was calculated as the ratio of the power (voltage $\times$ current) to the velocity of the heat source (the arc) as follows [10]:

$$
H=\frac{60 E I L}{1000 S},
$$

where $H, E$, and $I$ are the heat input in KJ, the arc voltage in volts, and the current in amps, respectively. $S$ is the travel speed in $\mathrm{mm} / \mathrm{min}$. $L$ is the length of weldments in millimeters. The welding current and the welding voltage were measured to be $120 \mathrm{~A}$ and $20 \mathrm{~V}$, respectively.

In this investigation, it was found that the travel speed of $45 \mathrm{~mm} / \mathrm{min}$ for FSW and GMAW is almost similar. The results showed that for FSW sound defect free welds were obtained as opposed to GMAW, where a weld defect was detected.

The heat input per unit length of FSW process was calculated according to the following formula [6]:

$$
H=f \sigma_{y} A L,
$$

where $f$ is the ratio in which the heat generated at the tool shoulder/workpiece interface was transported between the tool and the workpiece, $\sigma_{y}$ is the yield stress of the metal at $0.8 T_{s}, T_{s}$ is the solidus temperature, and $A$ is the crosssectional area of the tool shoulder. $L$ is the length of the weldment. The value of $f$ for FSW of aluminum alloy with steel tool is found to be $>90 \%$. [6]. Accordingly, the heat input to weld the entire joint of $5 \mathrm{~cm}$ in length was calculated for both GMAW and FSW and it was found for GMAW to be four times that of FSW.

Sample preparation for metallography test was performed according to the ASTM E3 (Standard Guide of Metallographic Specimens) [13]. All samples (except for tensile test) were ground, polished, and etched for macrostructure, microstructure, and microhardness test according to the ASTM E407 (Standard Practice for Microetching Metals and Alloys) [14]. The etchant used for aluminum alloys was Keller's reagent which is a mixture of $3 \mathrm{~mL}$ hydrochloric acid, $5 \mathrm{~mL}$ nitric acid, $2 \mathrm{~mL}$ hydrofluoric acid, and $190 \mathrm{~mL}$ distilled water.

The tensile test was conducted according to the standard test method for metallic materials (ASTM E8) [15]. The Vickers microhardness test $(\mathrm{Hv})$ was conducted according to the standard test for microhardness of metallic materials (ASTM E384) [16]. The hardness applied load was $1 \mathrm{~kg}$ and the dwell time was 8 seconds.

\section{Results and Discussion}

3.1. Characterization of the Surface and Root Joints. Figure 5 shows the profile of the Al-Al friction stir welded joints at a rotational speed of $1750 \mathrm{rpm}$ and traverse speed of $45 \mathrm{~mm} / \mathrm{min}$. Figure 5(a) reveals the weld profile at the top of the plate to be rough and spattered. The partially delaminated onion ring pattern is evident. This occurs due to insufficient heat generation in the shoulder rubbing action with the top surface of the plate [17]. In Figure 5(b) the lack of root penetration defect and the incomplete filled groove are

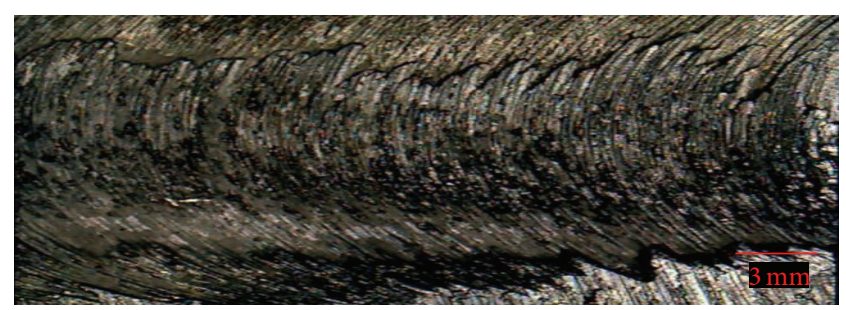

(a)

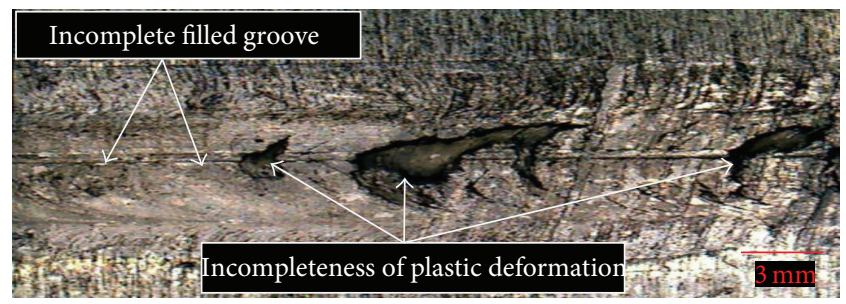

(b)

Figure 5: The weld profile of the Al-Al friction stir welded joints at a rotational speed of $1750 \mathrm{rpm}$ and traverse speed of $45 \mathrm{~mm} / \mathrm{min}$ at (a) the top side and (b) the bottom side.

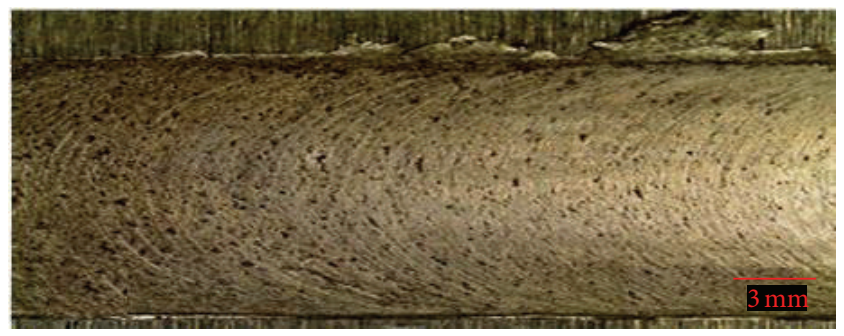

(a)

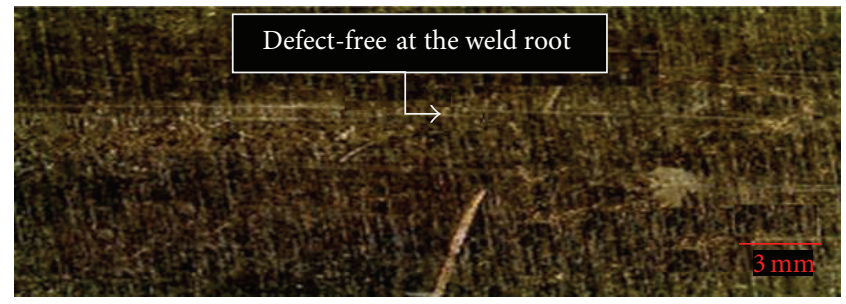

(b)

Figure 6: The weld profile of friction stir welded Al-Al joint at rotational speed of $2720 \mathrm{rpm}$ and traverse speed of $45 \mathrm{~mm} / \mathrm{min}$ at (a) top side and (b) bottom side.

eminent. This might be attributed to the shortness of the pin which resulted in poor penetration down to the bottom of the welded piece which in turn resulted in an insufficient heat flow, one that is necessary to deform, plasticize, and join the bottom sides together. The pin plunging depth is a critical factor and difficult to be controlled. The depth of sinking must be constant during the welding process. However, that is very difficult to achieve without assuring a horizontal surface leveling particularly for joining long workpieces [18].

Figure 6 shows the profile of the Al-Al friction stir welded joints at a rotational speed of $2720 \mathrm{rpm}$. Figure 6(a) depicts 


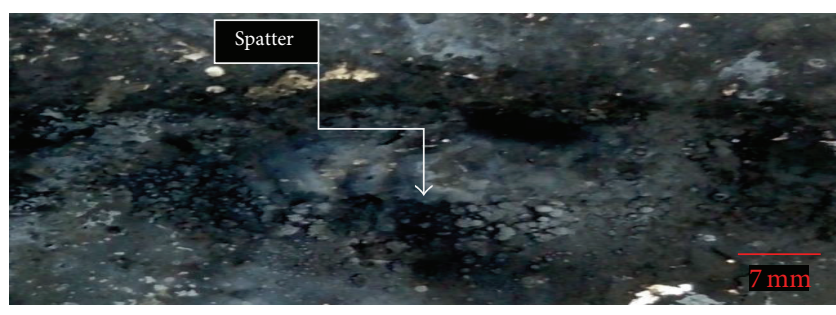

(a)

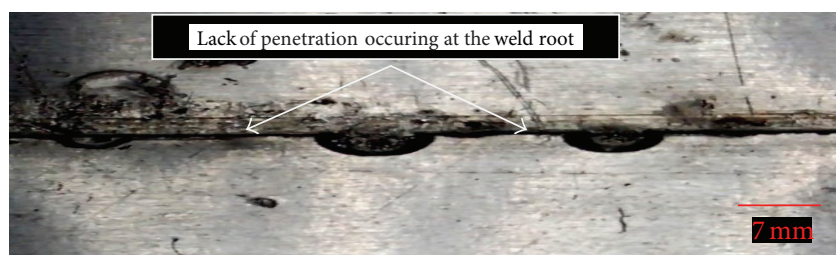

(b)

Figure 7: The weld profile of the Al-Al GMAW welded joint at (a) the top side and (b) the bottom side.

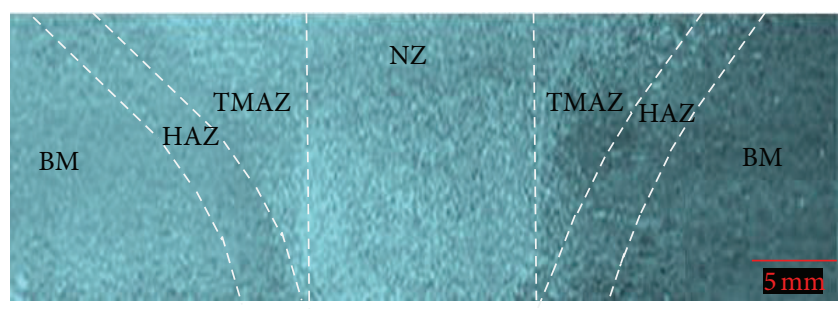

FIgURE 8: Optical image showing the macroscopic features in a cross section of the FSW butt joint.

much smoother tightly striated weldment profile compared to that joint conducted at a rotational speed of $1750 \mathrm{rpm}$. Figure 6(b) shows the bottom side of the plate; it reflects a defect-free surface. This was due to sufficient heat received on both top and bottom sides of the plate which enhanced the plasticizing of the aluminium piece during welding. Higher rotational speeds can afford better weld profile even though both the traverse speed and the applied load are kept constant [17].

Figure 7(a) shows the weld profile of the Al-Al GMAW joint at its top side. Spatters around the welded metals are evident. This might be caused by an excessive current, arc blow, damp electrode, contamination, and/or incorrect wire feed speed during the welding process. Figure 7 (b) clearly shows that there is a significance of the lack of penetration occurring at the weld root of the plate. This is probably caused by the high welding speed which results in insufficient heat provisioning and is not enough to melt the bottom of the plate [19].

3.2. Microstructures Analysis. The optical low magnification image in Figure 8 shows the main features of the FSW process at the NZ. The NZ reflects a basin-like nugget zone shape. The formation of this shape on FSW is attributed to the maximal deformation and plasticization in the material of the upper part of the NZ as opposed to that of its lower parts. The NZ in the pin shoulder side receives the uttermost amount of the frictional heat generated by the intimate contact of its surface with the cylindrical-tool shoulder. Hence it yields, flows, and flattens under the pin swirling action more than its lower part on the anvil side does and results in this basinlike nugget shape. However, so far various shapes of NZ have been observed. The evolution of the NZ shape depends on the processing parameter, tool geometry, and thermal gradient in the workpiece. Mahoney et al. [20] reported elliptical nugget zone shape in the weld of the 7075-T651 aluminum alloy rather than a basin-like shape.

Figure 9 shows the microstructure at different welding regions of the Al-Al FSW joints at a rotational speed of $1750 \mathrm{rpm}$. Figure 10 shows the microstructure at different welding regions of the Al-Al FSW joints with a rotational speed of $2720 \mathrm{rpm}$. Figures 9(a) and 10(a) show the microstructure of the original as-received base metal. The randomly distributed second phase particles appeared as small black particles. Elongation of the Al grains along the rolling direction is evident. During FSW, the base metal experiences no metallurgical changes and maintains its original cold-worked microstructure. Figures 9(b) and 10(b) show that the two NZs of the weld joints resulted from the two different rotational speeds. NZ produced at $2720 \mathrm{rpm}$ has a smaller grain size as opposed to that conducted at a speed of $1750 \mathrm{rpm}$. These variations result from excess heat exposure and the intensive stirring action induced at higher rotational speeds.

Figures $9(\mathrm{c})$ and 10 (c) show the NZ and the TMAZ at the two rotational speeds. It is prominent that the grain size at TMAZ is larger than the grain size at NZ. Regarding the grain size phylogeny at the NZ and the TMAZ, there are two conflicting factors acting together and affecting this process. During welding, the grains at these two regions undergo plastic deformations, mechanical shearing, and thermal exposure. Hence, they get plasticized, extruded, and rotated according to the strain levels to which they are subjected [21]. The mechanical actions of deformation, shearing, and extrusion result in smaller grain size, while the thermal exposure acts as grain size promoter. In the NZ, the mechanical actions are more severe and the outcome of these conflicting actions work in favor of dynamic recrystallization resulting in small grain size, smaller than that at the BM, TMAZ, and HAZ. This mechanical action is augmented at higher speeds and results in even smaller grain size. The TMAZ is located slightly further away from the direct effect of the rotating pin action. It is characterized by a highly deformed structure. Although the TMAZ undergoes plastic deformation, but dynamic crystallization does not occur in this zone due to insufficient deformation and strain. Consequently the thermal and mechanical interactions work in favor of thermal effect and result in grain growth. Higher rotational speed favors larger grain size. The grain size decreases as the input heat decreases.

Figures 9(d) and 10(d) show the TMAZ and the HAZ of the $\mathrm{Al}-\mathrm{Al}$ welded joints. The grains at the $\mathrm{HAZ}$ are coarser as opposed to those at the TMAZ. The thermal exposure causes 


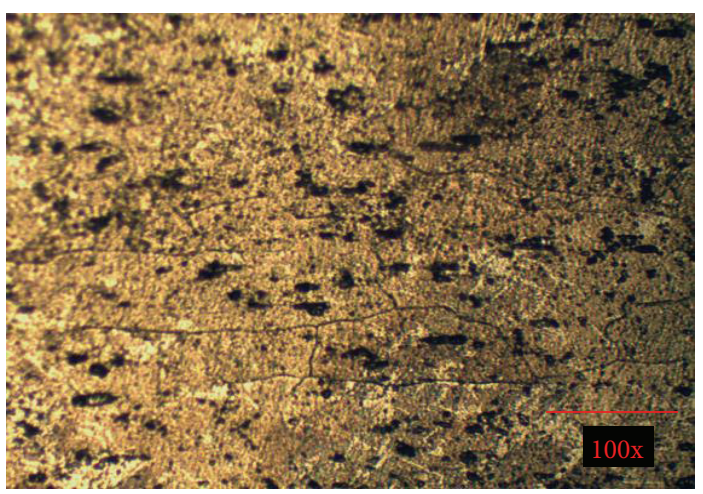

(a)

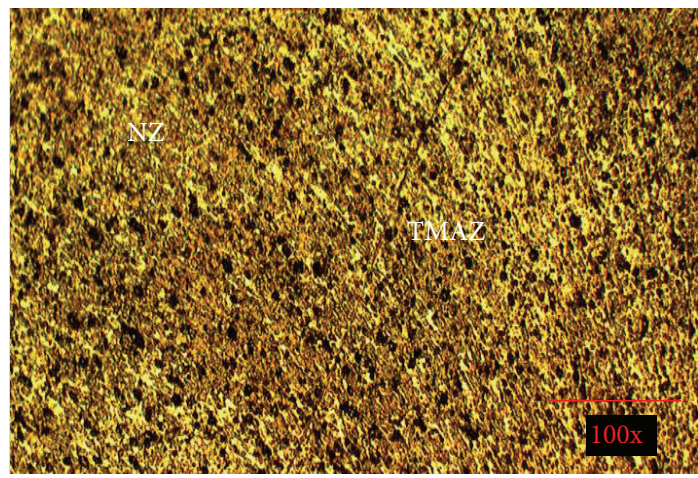

(c)

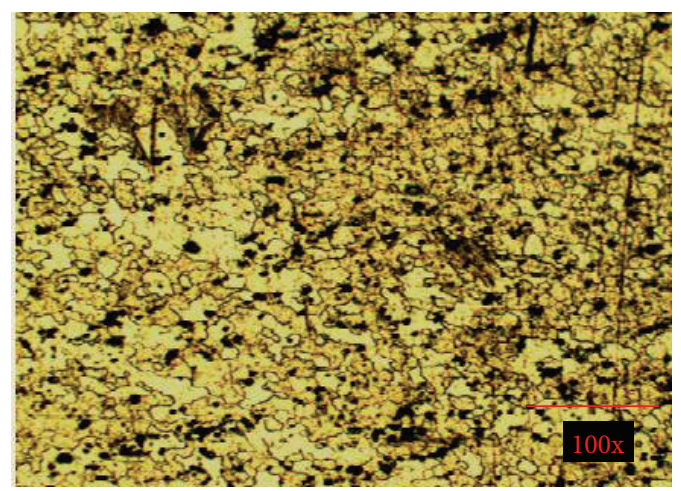

(b)

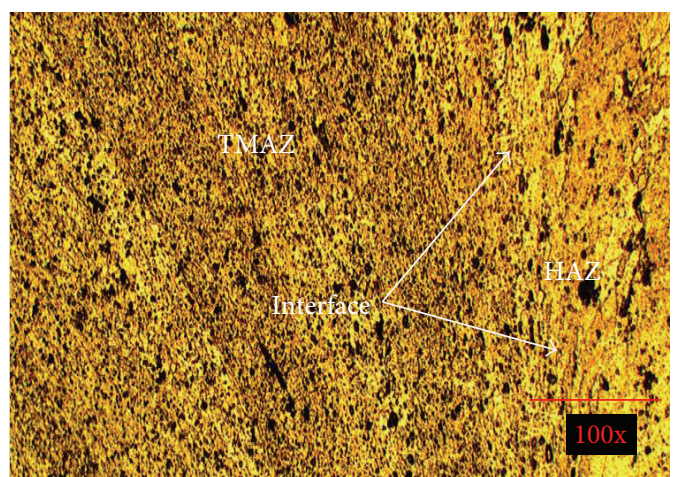

(d)

FIGURE 9: Optical images reveal the microstructures of different welding zones on Al-Al butt welded joint performed by the FSW technique at a rotational speed of $1750 \mathrm{rpm}$. (a) BM, (b) NZ, (c) NZ and TMAZ, and (d) TMAZ and HAZ 100x magnification.

TABLE 1: Grain size at different welding zones for FSW and GMAW for Al-Al joints.

\begin{tabular}{|c|c|c|c|c|}
\hline \multirow{2}{*}{ Items } & \multicolumn{4}{|c|}{ Range of grain size in $\mu \mathrm{m}$ of the weld regions } \\
\hline & NZ/WZ & TMAZ & HAZ & $\mathrm{BM}$ \\
\hline \multicolumn{5}{|l|}{ FSW } \\
\hline \multicolumn{5}{|c|}{ Rotational speed } \\
\hline $1750 \mathrm{rpm}$ & $3.5-10$ & $3-11$ & $8-18$ & $5-16$ \\
\hline $2720 \mathrm{rpm}$ & $2-8$ & $3.5-13$ & $8-19$ & $5-16$ \\
\hline GMAW & $7-12$ & - & $10-22$ & $5-16$ \\
\hline
\end{tabular}

the grains to grow. The grains become coarser as they are located further away from the center of the NZ.

The grain size at different welding regions for the two FSW Al-Al joints conducted at 1750 and $2720 \mathrm{rpm}$ is shown in Table 1. The relation between grain size and mechanical properties can be expressed by the following Hall-Petch equation [22]:

$$
\sigma=\sigma_{0}+K_{h} d^{-1 / 2}
$$

where $\sigma$ is the strength of the material, $d$ is the grain size diameter, $\sigma_{0}$ and $K_{h}$ are experimental constants and are different for each metal. Equation (3) shows that smaller grain size diameter results in higher microhardness and UTS of the material. Besides, the mechanical properties not only depend on the degree of grain refinement. And in addition, secondary phase formation, microstructure homogeneity, and microstructure defects play a vital role in deciding the mechanical properties of the weld joint.

For GMAW, the solidified weld pool and the corresponding heat affected base metal are called the welding zone (WZ) and the heat affected zone (HAZ), respectively. Partially melted zone (PMZ) in the interface of WZ and HAZ is also found in the case of some specific nonferrous alloys. The width of these zones is a direct function of the input heat and material's thermal conductivity. The cooling rate and peak temperature primarily dictate the solidification mode and phase content of the weld microstructure. The initial grain morphology is found to be columnar dendrites and develop with a different inclination to equiaxed dendritic [23].

Figure 11 shows the microstructures of (a) BM and (b) WZ and HAZ of a weld joint produced by GMAW similar to that produced by FSW. Evolution of dendritic structure in WZ is attributed to the fast heating of the weld zone up to the melting temperature and the subsequent fast cooling of the molten pool [24]. However, FSW requires much lower heat input and welding power compared to the arc welding process. Less heat input helps improve the joint mechanical properties and decreases both distortion and residual stresses [19]. 


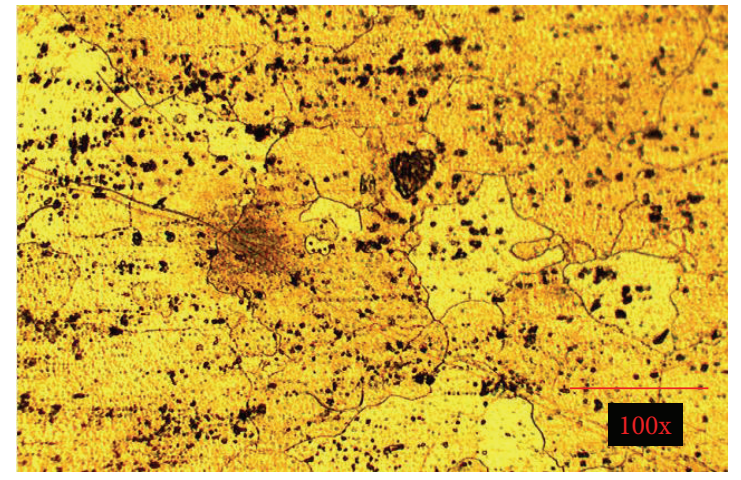

(a)

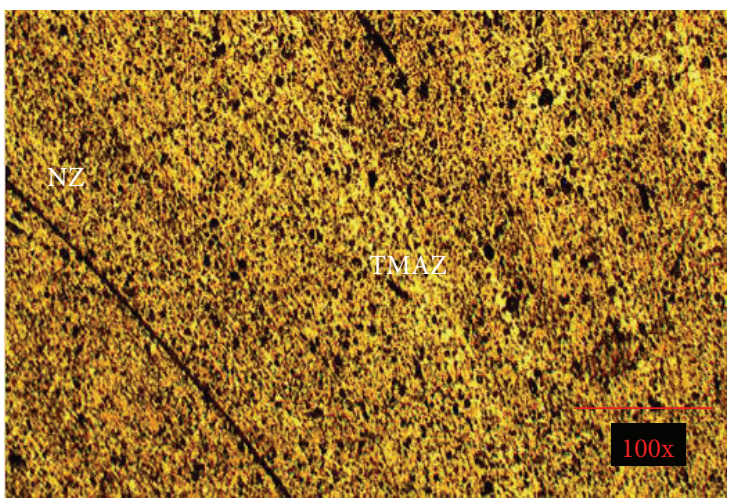

(c)

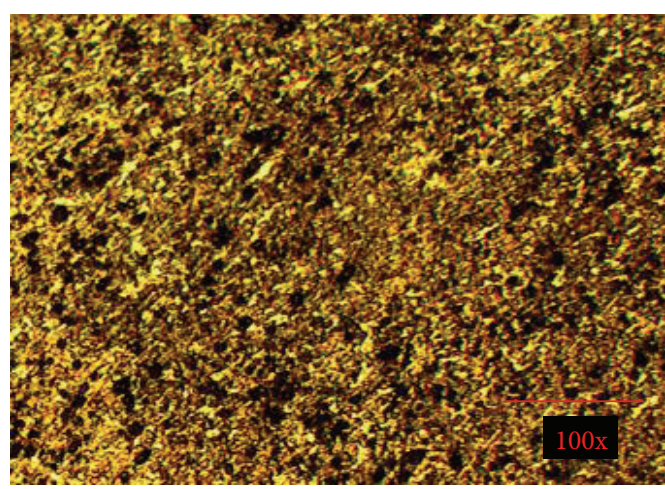

(b)

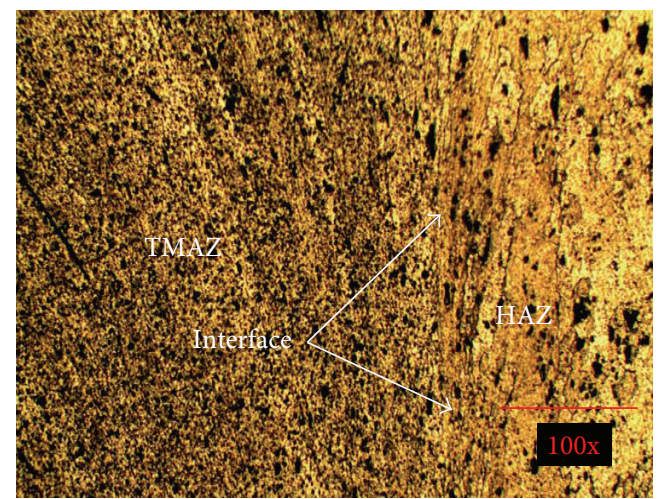

(d)

FIGURE 10: Optical images reveal the microstructures of different welding zones on Al-Al butt welded joint performed by FSW at a rotational speed of $2720 \mathrm{rpm}$. (a) BM, (b) NZ, (c) NZ and TMAZ, and (d) TMAZ and HAZ 100x magnification.
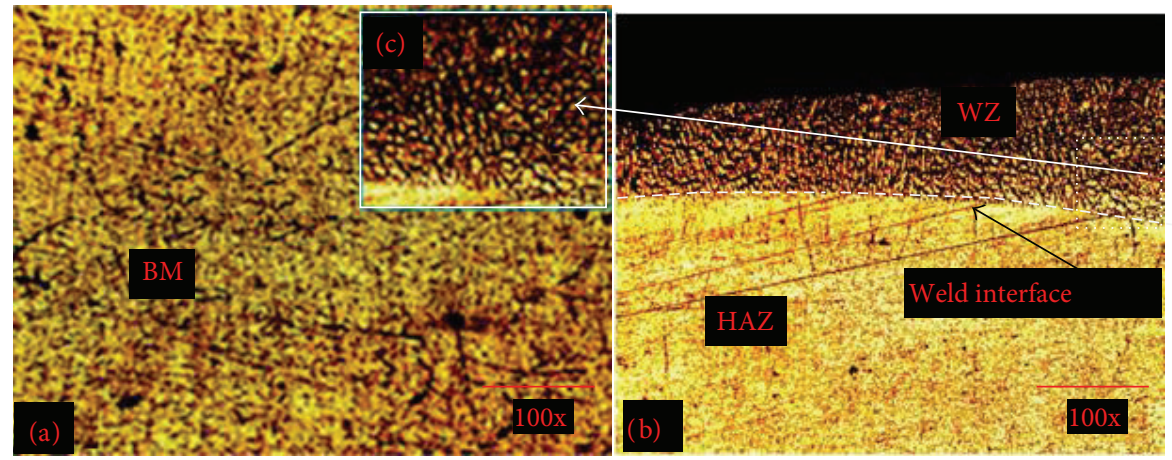

FIGURE 11: The welding morphology of the Al-Al GMAW joint depicts the microstructure of the (a) BM and (b) WZ and HAZ. The transition of grain structure from columnar dendritic to equiaxed dendritic is illustrated in the enlarged region of WZ in (c).

3.3. Environmental Effects of FSW and GMAW Techniques. Indoor Air Quality Pro device was used to detect and analyze the amount of emitted gases during the welding process. The amounts of the detected gases for both FSW and GMAW processes were compared to determine which welding technique results in the release of more harmful gases to the surroundings. The measured amount of carbon dioxide and carbon monoxide gases prior to welding and after welding is shown in Table 2 . To assure reliable results, the measurements were conducted in a closed confined volume of $7.2 \mathrm{~m}^{3}$ welding stalls.
3.4. Scanning Electron Microscopy (SEM) Analysis. Figure 12 shows an SEM image coupled with EDX scan analysis of the $\mathrm{NZ}$ of Al-Al FSW joint produced at a rotational speed of $2720 \mathrm{rpm}$. Weak peaks of carbon and oxygen can be seen in the EDX plot analysis; oxidization of the Al-Al welded joints at the NZ is expectable. High frictional heat generation and atmosphere humidity of $75 \%$ enhance oxidation of aluminum during the welding process. Existence of carbon in the NZ may be attributed to the contamination from the medium carbon steel tool during the welding process. Surprisingly Fe was not detected by the EDX analysis. However, its existence 

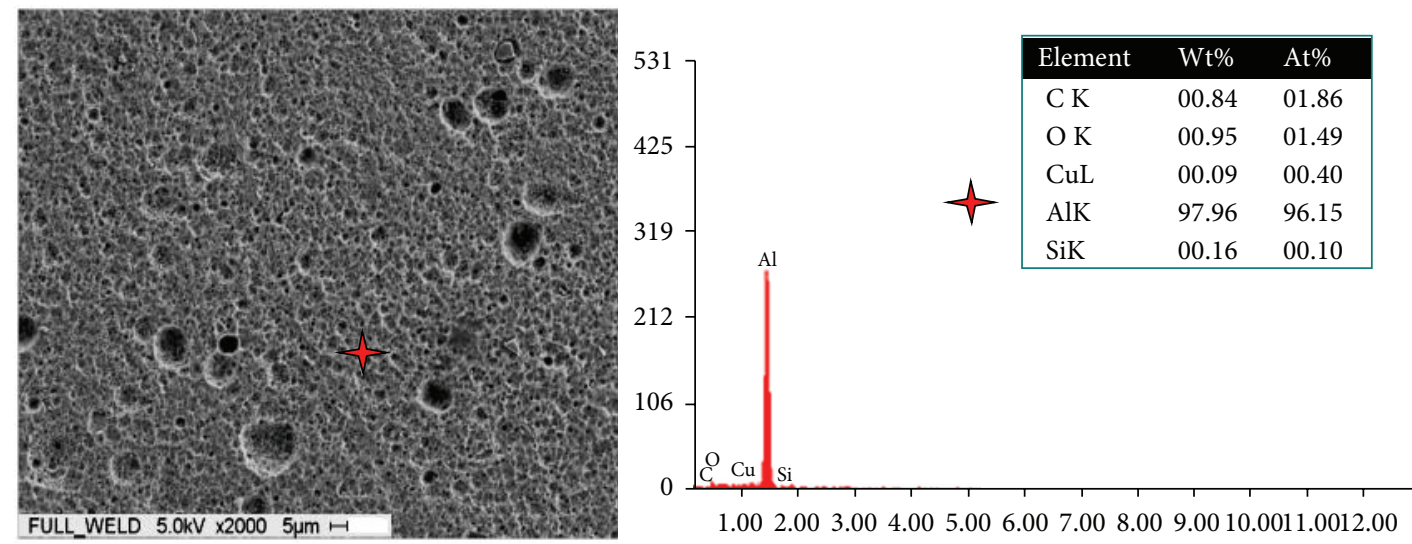

FIGURE 12: SEM image and EDX analysis of the NZ of Al-Al FSW joint performed at a rotational speed of $2720 \mathrm{rpm}$.

TABLE 2: The amounts of the released gases in the welding area prior to and after welding.

\begin{tabular}{|c|c|c|c|c|c|c|}
\hline \multirow{2}{*}{ Number of tests } & \multicolumn{2}{|c|}{ Atmosphere } & \multicolumn{2}{|c|}{ GMAW } & \multicolumn{2}{|c|}{ FSW } \\
\hline & $\begin{array}{c}\text { Carbon monoxide } \\
{[\mathrm{ppm}]}\end{array}$ & $\begin{array}{c}\text { Carbon dioxide } \\
{[\mathrm{ppm}]}\end{array}$ & $\begin{array}{c}\text { Carbon } \\
\text { monoxide }[\mathrm{ppm}]\end{array}$ & $\begin{array}{c}\text { Carbon dioxide } \\
\text { [ppm] }\end{array}$ & $\begin{array}{c}\text { Carbon } \\
\text { monoxide }[\mathrm{ppm}]\end{array}$ & $\begin{array}{c}\text { Carbon dioxide } \\
\text { [ppm] }\end{array}$ \\
\hline 1 & 0.4 & 121 & 2.8 & 361 & 0.5 & 197 \\
\hline 2 & 0.3 & 118 & 2.0 & 354 & 0.3 & 241 \\
\hline 3 & 0.5 & 122 & 2.2 & 344 & 0.6 & 196 \\
\hline 4 & 0.7 & 119 & 2.7 & 338 & 0.7 & 201 \\
\hline 5 & 0.9 & 117 & 3.9 & 333 & 1.0 & 223 \\
\hline
\end{tabular}

within the NZ is confirmed by the X-ray diffraction (XRD) analysis.

3.5. X-Ray Diffraction (XRD) Analysis. XRD analysis was performed on the base metal and the NZ for the two rotating speeds. The resulting superimposed diffraction patterns are displayed in Figure 13. Besides, $\alpha \mathrm{Al}$ existence of different intermetallic phases at the NZ of the two rotating speeds is evident. These intermetallic phases often have complex lattice structures and microhardness values. The Al-Fe-Si ternary system is the key for $\mathrm{Al}$ alloy family phase formation. The formation of different Al-Fe and Al-Fe-Si intermetallic phases at different rotating speeds is attributed to the amount of heat input and the Fe content in the nugget zone. Stirring action at different rotating speeds leads to transferring of different $\mathrm{Fe}$ amounts from the steel tool to the welded piece and eventually results in the formation of different intermetallic phases at various temperatures. Despite the high hardness of these intermetallic phases, they have some negative effects, especially that of Al-Fe intermetallic such as $\mathrm{Al}_{13} \mathrm{Fe}_{4}$ and $\mathrm{AlFe}_{3}$. The large electrochemical potential of 1.22 volts between iron and aluminum results in higher susceptibility to intercrystalline and galvanic corrosion [25].

$\mathrm{X}$-ray diffraction analysis was performed also to identify the phases of the Al-Al GMAW joints. According to the XRD analysis the usage of the filler wire does not affect on the phase transformation. This may be attributed to the difference in phase formation mechanisms between FSW and GMAW processes. The XRD pattern in Figure 14 reveals that mainly pure $\mathrm{Al}$ phase is present.
3.6. Tensile Test. Figure 15 clearly illustrates the inferior strength of all weld joints as opposed to the UTS of the base metal. Among the three fabricated weld joint sets, the Al-Al FSW joints conducted at a speed of $2720 \mathrm{rpm}$ gave the highest tensile strength. This was due to the grain refinement; homogeneous and defect-free microstructure of the joint resulted from the very intense stirring action at high rotational speed. The Al-Al FSW joints conducted at a speed of $1750 \mathrm{rpm}$ have slightly inferior tensile strength as compared to that conducted at $2720 \mathrm{rpm}$ speed. The tensile tests demonstrated that fractures mainly occurred at the boundary between the nugget and the TMAZ rather than along interface within the nugget itself.

The Al-Al GMAW joint possesses the low tensile strength as compared to the other fabricated weld joints. The reduction in the UTS of this weld was about $85.7 \%$. It only possessed about $19.7 \%$ and $17.7 \%$ of the UTS of the welded joints fabricated by the FSW technique at the two rotation speeds of $1750 \mathrm{rpm}$ and $2720 \mathrm{rpm}$, respectively. This high reduction in the tensile strength experienced by the GMAW joints thought to be due to the evolution of many defects during the melting and solidification process such as impurities, cracks, and pores adversely affects mechanical properties.

3.7. Microhardness Test. Figure 16 depicted that the microhardness at the NZ, TMAZ, and HAZ for the FSW Al-Al joints is lower than the microhardness of the BM. This is attributed to the effects of thermal exposure and mechanical action which lead to different levels of dynamic recrystallization, grain growth, and phase transformation at the different 


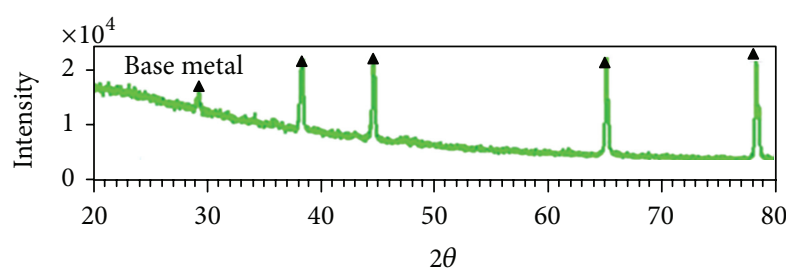

$\triangle \mathrm{Al}$

(a)

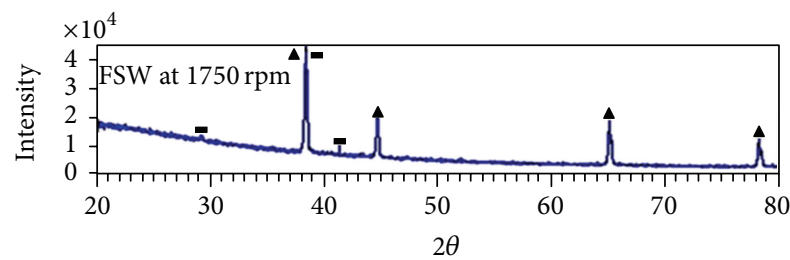

$\triangle \mathrm{Al}$

- $\mathrm{Al}_{13} \mathrm{Fe}_{4}$

(b)

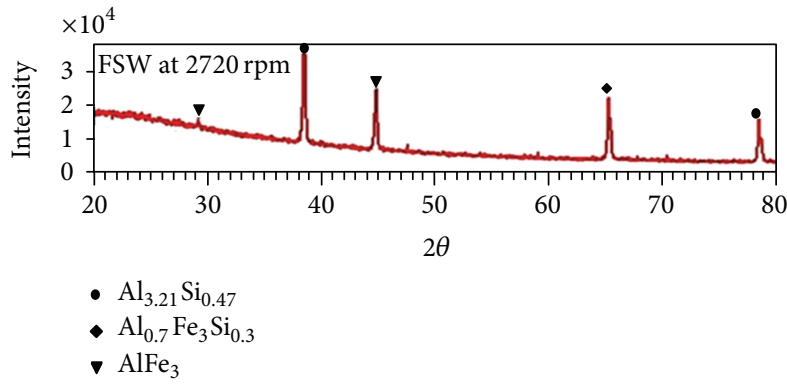

(c)

FIGURE 13: X-ray superimposed diffraction patterns of the Al-Al FSW joint. (a) BM and (b) NZ at rotating speed of $1750 \mathrm{rpm}$ and (c) $\mathrm{NZ}$ at rotating speed of $2720 \mathrm{rpm}$.

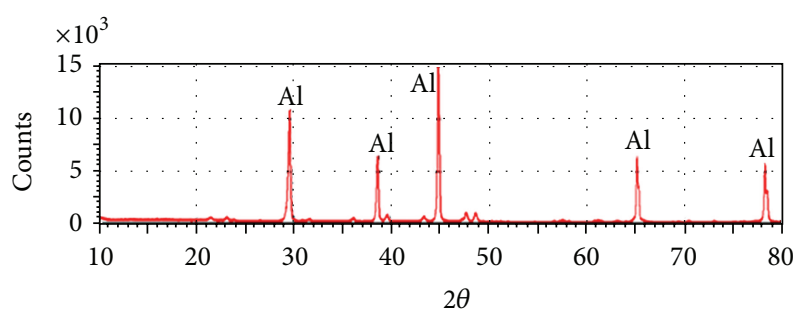

FIGURE 14: X-ray diffraction pattern of the Al-Al GMAW joint. Mainly peaks of pure $\alpha \mathrm{Al}$ are eminent.

welding zones. Recrystallization occurs when new grains form and consume the original cold-worked grains. The higher microhardness and strength of the BM are ascribed to the cold working gained during the production stages of casting, rolling, and forming. Cold working enhances microhardness and strength. It causes dislocations to be entangled with one another and hinders their motion [26].

The NZ showed the highest microhardness values as compared to other weld zones. HAZ showed the lowest hardness values. In fact, this is understandable. The HAZ is

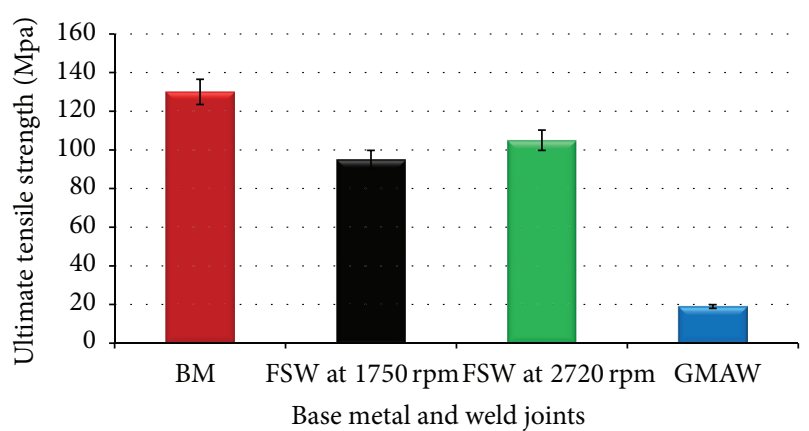

FIGURE 15: The UTS of the base metal and the weld joints produced by the FSW and the GMAW techniques.

Graph of microhardness against distance from the weld centre for friction stir welded Al-Al

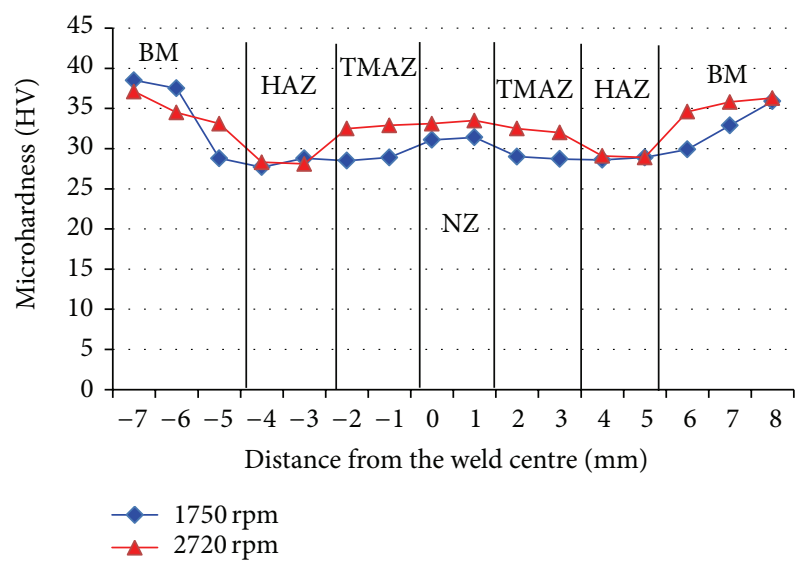

FIGURE 16: The microhardness profiles of Al-Al joints fabricated by FSW.

far away from the stirring action influence. This justifies why the microhardness values of the HAZ at the two rotational speeds were almost identical.

Figure 17 exhibits the microhardness profile for the Al-Al GMAW joints. Again the microhardness values of the weld zones are much lower than that of the BM. The elongated dendritic and the equiaxed grain structure with the WZ result in the fast heating and subsequent fast cooling of the molten pool. The bulk volume of the workpiece acts as an efficient sink for the heat generated during welding and results in different cooling rates at the HAZ and the WZ [27]. The heat flow gradient affects the mechanical properties of the joint. The HAZ demonstrated lower hardness than that of the WZ specifically near the weld interface. The weld interface is a narrow boundary that separates the $\mathrm{WZ}$ and the HAZ. It consists of a thin band of the BM that has melted or partially melted during the welding process but has immediately solidified before any mixing could take place.

\section{Conclusions}

(1) In this study FSW technique showed outstanding advantages over the GMAW process in joining $1030 \mathrm{Al}$ alloys. It gave 


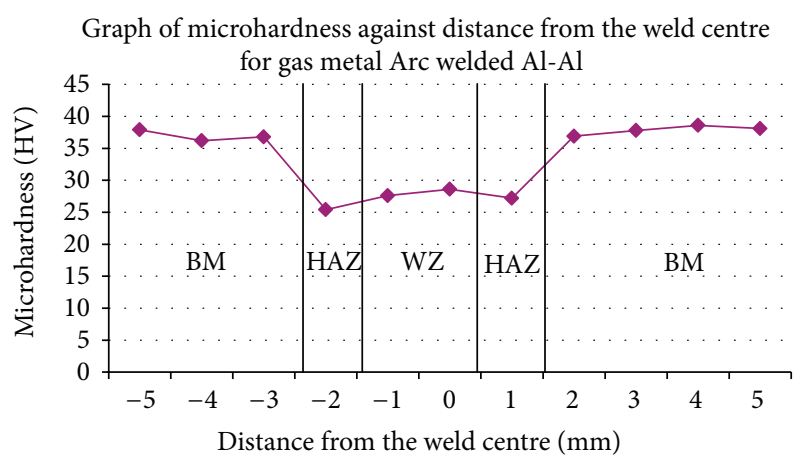

FIGURE 17: The microhardness profiles of $\mathrm{Al}-\mathrm{Al}$ joint fabricated by GMAW.

clean, defect-free, and better weldment microstructure which in turn resulted in superior mechanical properties.

(2) FSW showed a substantial saving in power consumption. The power consumed in GMAW was fourfold that of FSW for execution of similar joints. This resulted in a reduction in the area where microhardness changes. The HAZ in FSW was narrower than that in GMAW process.

(3) GMAW process released higher amounts of harmful gases such as carbon monoxide and carbon dioxide to the surroundings (2.7 ppm and $346 \mathrm{ppm}$, resp.) as opposed to $0.6 \mathrm{ppm}$ and $211.6 \mathrm{ppm}$, respectively, for FSW.

(4) The joints welded by GMAW process exhibited substantial reduction in their UTS and microhardness values, $80 \%$ and $12 \%$, respectively, as opposed to FSW joints executed at rotation speed of $2720 \mathrm{rpm}, 78 \%$ and $9.5 \%$, respectively, as opposed to FSW joints executed at $1750 \mathrm{rpm}$.

\section{Conflict of Interests}

The authors declare that there is no conflict of interests regarding the publication of this paper.

\section{Acknowledgments}

This work is supported under the Grant no. 9001-00338 of the Universiti Malaysia Perlis (UniMAP). The authors gratefully acknowledge the outstanding support provided by the technicians of the workshop in the Materials Engineering School, UniMAP.

\section{References}

[1] R. K. Shukla and P. K. Shah, "Comparative study of friction stir welding and tungsten inert gas welding process," Indian Journal of Science and Technology, vol. 3, no. 6, pp. 667-671, 2010.

[2] E. D. Nicholas, "Friction stir welding-a decade on," in Proceedings of the IIW Asian Pacific International Congress, Sydney, Australia, October-November 2000.

[3] O. Vladvoj, S. Margarita, F. D. S. Jorge, and V. Pedro, "Microstructure and properties of friction stir welded aluminium alloys," in Paper Presented at Metal, Hradec nad Moravicí, Czech Republic, 2005.
[4] A. V. Kumar and K. Balachandar, "Effect of welding parameters on metallurgical properties of friction stir welded aluminium alloy 6063-O," Journal of Applied Sciences, vol. 12, no. 12, pp. 1255-1264, 2012.

[5] W. H. Jiang and R. Kovacevic, "Feasibility study of friction stir welding of 6061-T6 aluminium alloy with AISI 1018 steel," Proceedings of the Institution of Mechanical Engineers B: Journal of Engineering Manufacture, vol. 218, no. 10, pp. 1323-1331, 2004.

[6] G. G. Roy, R. Nandan, and T. DebRoy, "Dimensionless correlation to estimate peak temperature during friction stir welding," Science and Technology of Welding \& Joining, vol. 11, no. 5, pp. 606-608, 2006.

[7] T. Hirata, T. Oguri, H. Hagino et al., "Influence of friction stir welding parameters on grain size and formability in 5083 aluminum alloy," Materials Science and Engineering A, vol. 456, no. 1, pp. 344-349, 2007.

[8] J. N. Pires, A. Loureiro, and G. Bölmsjo, Welding Robots, Springer, London, UK, 2006.

[9] R. W. Messler, Principles of Welding: Processes, Physics, Chemistry, and Metallurgy, John Wiley \& Sons, New York, NY, USA, 2008.

[10] S. Kou, Welding Metallurgy, Wiley-Interscience, Hoboken, NJ, USA, 2nd edition, 2003.

[11] M. Esmaily, S. N. Mortazavi, P. Todehfalah, and M. Rashidi, "Microstructural characterization and formation of $\alpha$ martensite phase in Ti-6Al-4V alloy butt joints produced by friction stir and gas tungsten arc welding processes," Materials and Design, vol. 47, pp. 143-150, 2013.

[12] P. B. Anjaneya and P. Prasanna, "Experimental comparison of the MIG and friction stir welding processes for AA 6061(Al $\mathrm{Mg} \mathrm{Si} \mathrm{Cu}$ ) aluminium alloy," International Journal of Mining, Metallurgy \& Mechanical Engineering, vol. 1, no. 2, pp. 137-140, 2013.

[13] ASTM Standard E3, "Standard Guide for Preparation of Metallographic Specimens".

[14] ASTM Standard E407, "Standard Practice for Microetching Metals and Alloys".

[15] ASTM Standard E8, "Standard Test Methods for Tension Testing of Metallic Materials".

[16] ASTM Standard E384, "Standard Test Method for Knoop and Vickers Hardness of Materials".

[17] P. Bahemmat, A. Rahbari, M. Haghpanahi, and M. K. Besharati, "Experimental study on the effect of rotational speed and tool pin profile on AA2024 aluminum friction stir welded butt joints," pp. 1.1-1.7, Proceedings of the ASME Early Career Technical Conference (ECTC '08), Miami, Fla, USA, October 2008.

[18] C. Meran, "The joint properties of brass plates by friction stir welding," Materials \& Design, vol. 27, no. 9, pp. 719-726, 2006.

[19] S. R. McLaughlin, C. J. Bayley, and N. M. Aucoin, "Assessment of microstructural heterogeneities in multipass pulsed gas metal arc welds," Canadian Metallurgical Quarterly, vol. 51, no. 3, pp. 294-301, 2012.

[20] M. W. Mahoney, C. G. Rhodes, J. G. Flintoff, W. H. Bingel, and R. A. Spurling, "Properties of friction-stir-welded 7075 T651 aluminum," Metallurgical and Materials Transactions A, vol. 29, no. 7, pp. 1955-1964, 1998.

[21] G. Liu, L. E. Murr, C.-S. Niou, J. C. McClure, and F. R. Vega, "Microstructural aspects of the friction-stir welding of 6061-T6 aluminum," Scripta Materialia, vol. 37, no. 3, pp. 355-361, 1997. 
[22] J. W. Dini, Electrodeposition: The Materials Science of Coatings and Substrates, Noyes Publications, Park Ridge, NJ, USA, 1993.

[23] P. Kamal and K. P. Surjya, "Effect of pulse parameters on weld quality in pulsed gas metal arc welding: a review," Journal of Materials Engineering and Performance, vol. 20, no. 6, pp. 918931, 2011.

[24] Y. Liu, W. Wang, J. Xie et al., "Microstructure and mechanical properties of aluminum 5083 weldments by gas tungsten arc and gas metal arc welding," Materials Science and Engineering A, vol. 549, pp. 7-13, 2012.

[25] P. B. Srinivasan, K. S. Arora, W. Dietzel, S. Pandey, and M. K. Schaper, "Characterisation of microstructure, mechanical properties and corrosion behaviour of an AA2219 friction stir weldment," Journal of Alloys and Compounds, vol. 492, no. 1-2, pp. 631-637, 2010.

[26] H. J. McQueen, "Recovery and recrystallization during high temperature deformation," Treatise on Materials Science \& Technology, vol. 6, pp. 393-493, 1975.

[27] A. K. Lakshminarayanan, V. Balasubramanian, and K. Elangovan, "Effect of welding processes on tensile properties of AA6061 aluminium alloy joints," The International Journal of Advanced Manufacturing Technology, vol. 40, no. 3-4, pp. 286296, 2009. 

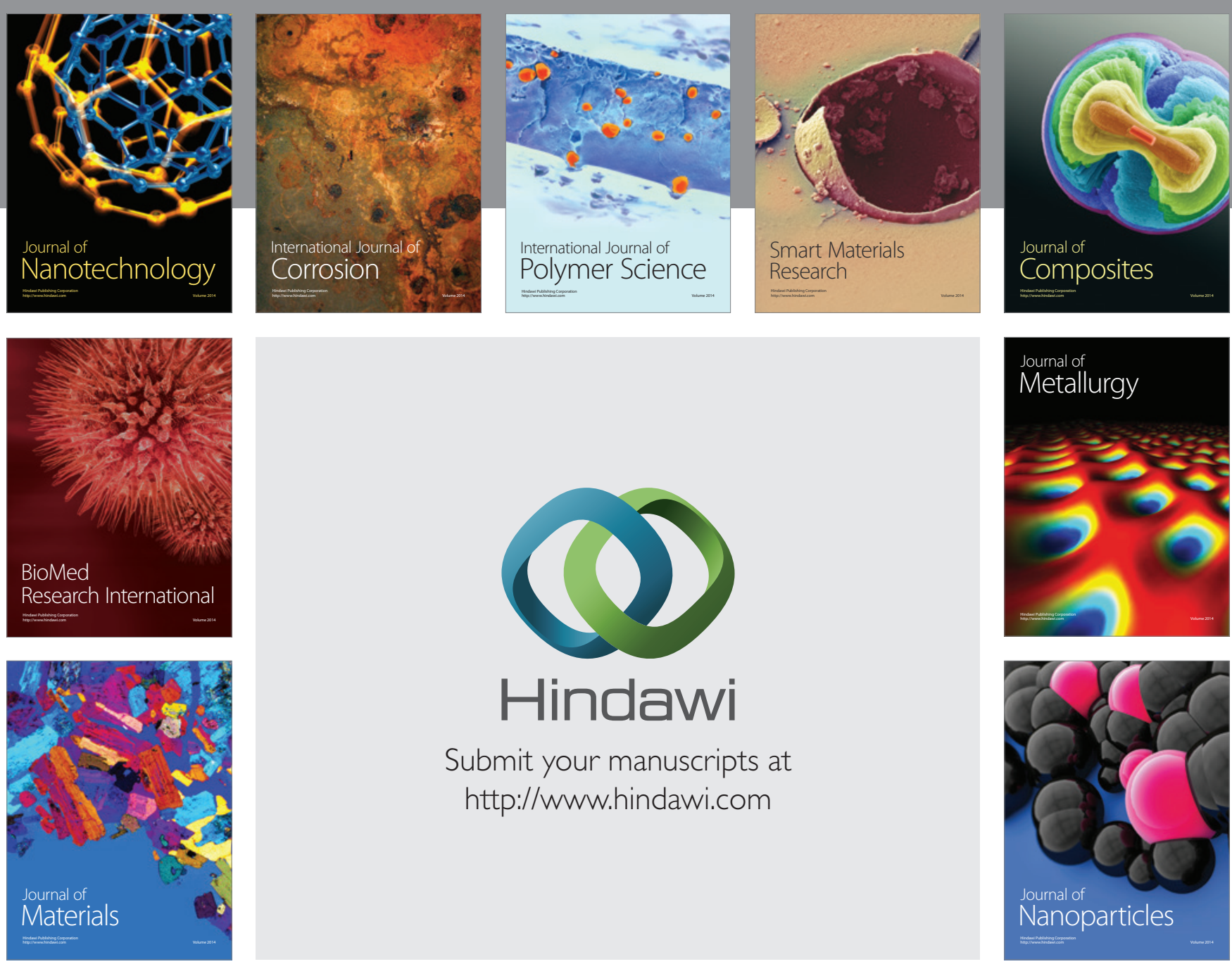

Submit your manuscripts at http://www.hindawi.com
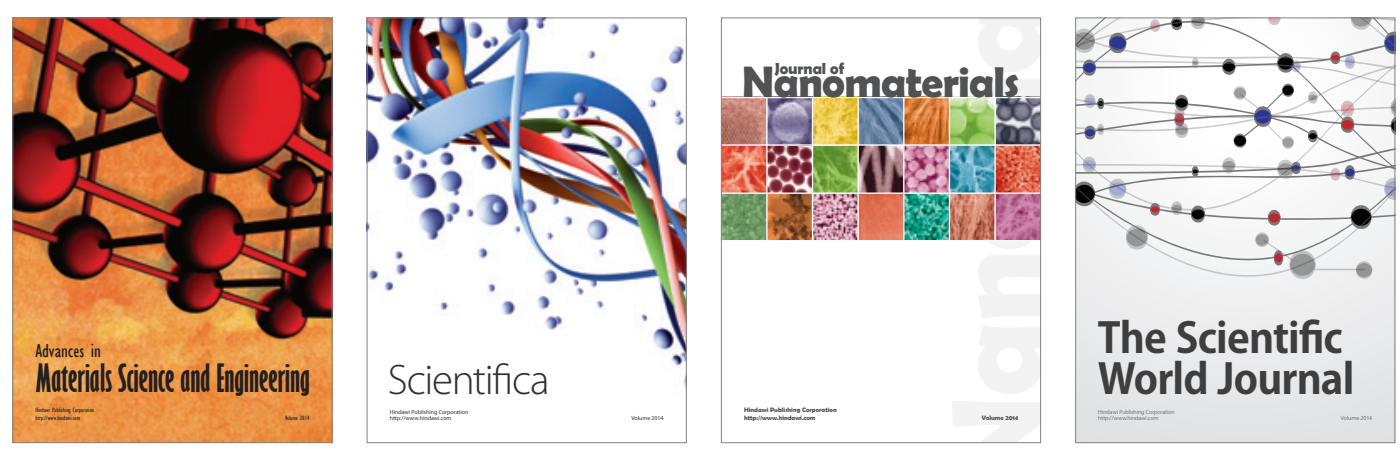

\section{The Scientific World Journal}
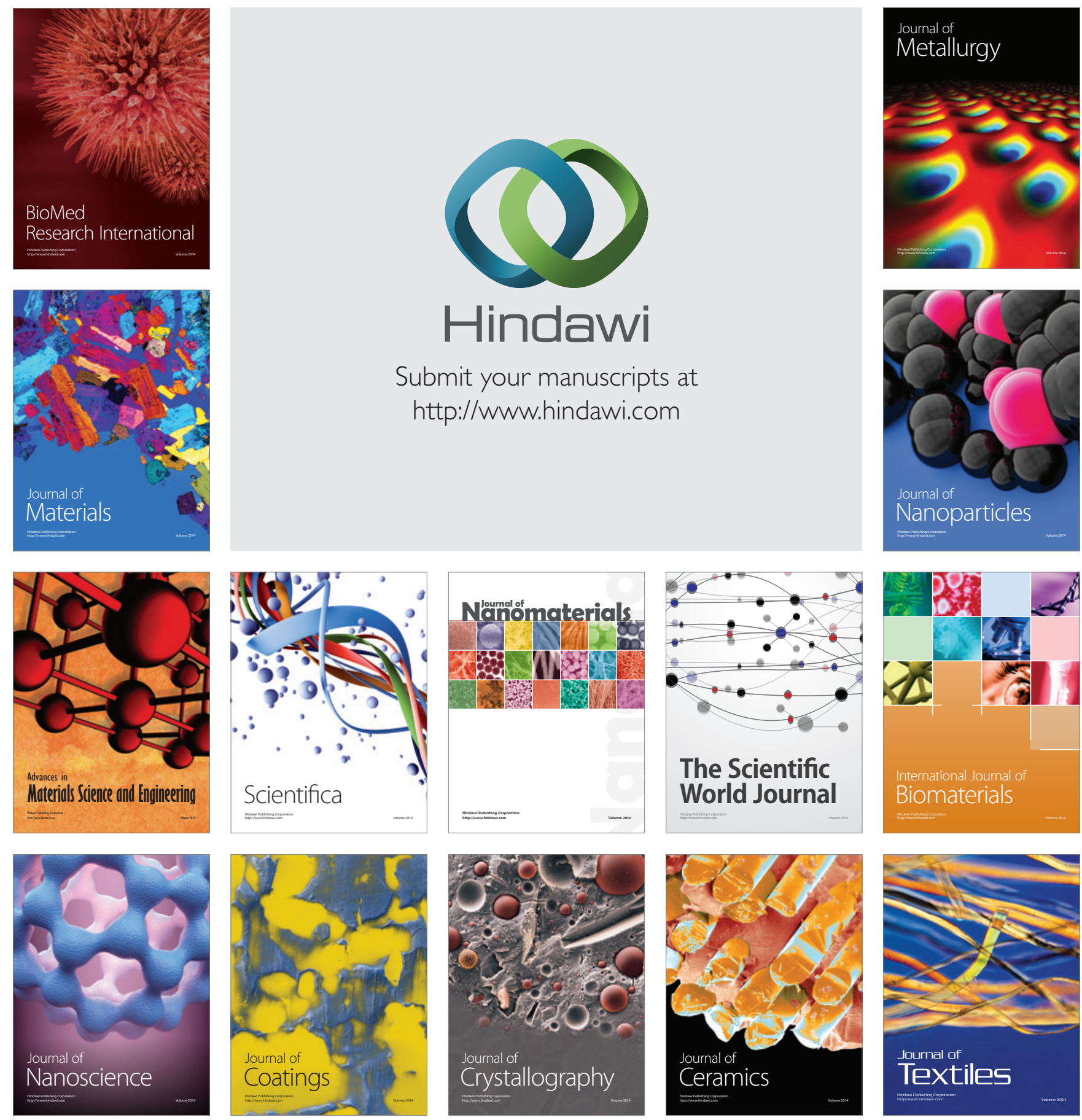